\title{
Effectiveness of defatted seed meals from Brassicaceae with or without crude glycerin against black grass (Alopecurus myosuroides Huds.)
}

by Matteo, R., Back, M.A., Reade, J.P.H., Ugolini, L., Pagnotta, E. and Lazzeri, L.

Copyright, Publisher and Additional Information: This is the author accepted manuscript. The final published version (version of record) is available online via Elsevier.

Please refer to any applicable terms of use of the publisher.

DOI: $\underline{\text { https://doi.org/10.1016/j.indcrop.2017.11.020 }}$

Matteo, R., Back, M.A., Reade, J.P.H., Ugolini, L., Pagnotta, E. and Lazzeri, L. 2017. Effectiveness of defatted seed meals from Brassicaceae with or without crude glycerin against black grass (Alopecurus myosuroides Huds.) Industrial Crops and Products, 111, pp.506-512 


\title{
1 Effectiveness of defatted seed meals from Brassicaceae with or without crude
}

2 glycerin against black grass (Alopecurus myosuroides Huds.)

3

*Corresponding Author Email: roberto.matteo@crea.gov.it

\begin{abstract}
Herbicide resistance has become an increasing problem, and at the same time pesticide usage is declining due to stringent EU pesticide legislation which aims to reduce the impact on environment and human health. For these reasons, new alternative integrated weed management approaches are becoming increasingly relevant. Formulations based on Brassica defatted seed meals (DSMs) and glycerin, have previously been shown to be effective in reducing the germination of lettuce seed. In this work five DSMs, formulated with and without crude glycerin, were chosen for in vitro and glasshouse experiments: i) Brassica nigra, ii) Brassica tournefortii, iii) Eruca sativa, iv) Rapistrum rugosum and v) Sinapis alba. Black-grass (Alopecurus myosuroides), a weed demonstrating extensive herbicide resistance, was used as a target, and the germination inhibition caused on this weed by Brassica defatted seed meals was assessed.

In both in vitro and in vivo experiments, the most effective DSM for inhibiting germination of both lettuce and black-grass seeds was the sinigrin containing DSM, Brassica nigra.
\end{abstract}


The aim of the manuscript was to suggest a new high value application for Brassicas derived DSM as a co-products from the vegetable oil production chain. The proposed treatments could represent an interesting and $100 \%$ novel natural alternative to the conventional herbicides.

Keywords: Alopecurus myosuroides, Bioeconomy, Germination inhibition, GlucosinolateMyrosinase System, Isothiocyanates, Weed Management

\section{Introduction}

Despite different land use contexts, from agriculture to urban settings, weed control remains a major problem. In particular, weed control in amenities such as parks and schools should be undertaken without threatening health and environment. At the same time, whilst herbicide resistance has become an increasing problem (Service, 2013), EU policy is demanding a significant reduction of pesticide usage. In fact, several high impact chemical products used in European agriculture are in phase out or under scrutiny following the Directive 2009/128/EC on "Sustainable use of pesticides", and the Regulation (CE) no. 1907/2006 (REACH) on Registration, Evaluation, Authorization and Restriction of Chemicals. In the Article 14 concerning Integrated Pest Management, the REACH clearly reports that "Member States shall take all necessary measures aimed at promoting low pesticide-input pest management, giving wherever possible priority to non-chemical methods".

At the same time, a wide range of fossil-based products could be substituted by bio-based products and materials derived from different biomasses such as energy crops, agricultural and forestry residues and waste (Maity, 2015).

The most abundant co-products of industrial vegetable oil production for bioenergy and green chemistry are defatted seed meals (DSMs) derived from seed defatting procedures. Among oilseed crops, biofumigant Brassicaceae crops have shown great potential within integrated pest management and organic farming solutions. In fact, some Brassica DSMs contain high level of 
glucosinolates (GSLs) and, after a patented procedure (Lazzeri et al., 2010), they proved to be suppressive against a variety of soil-borne fungal pathogens (Lazzeri et al., 2003), nematodes (Lazzeri et al., 2009; Ngala et al., 2015) and wire-worms (Furlan et al., 2010). In their native form, GSLs are stable and marginally reactive, while in the presence of water and the endogenous enzyme myrosinase (MYR) they are quickly hydrolyzed with the production of a series of bioactive breakdown products, mainly isothiocyanates (ITCs) and, to a lesser extent, nitriles, epithionitriles and thiocyanates, depending on the reaction conditions (Bones and Rossiter, 2006; Agerbirk and Olsen, 2012). Thanks to this natural process, Brassicaceae species have been widely studied for applications in the so called biofumigation technique (Kirkegaard et al., 1993). Since the inhibitory influence of aqueous extracts from parts of Brassica oleracea plants on the germination and growth of clover (Trifolium repens L.) and rye-grass (Lollium spp.) was first described by Campbell (1959), many other studies on the allelopathic effects of GSL degradation products were carried out. Angelini et al. (1998) reported a total inhibition of seed germination of different weeds by the hydrolysis products of glucoerucin and glucoraphanin. In the same study, seeds treated with the hydrolysis products of epi-progoitrin, mainly 5-vinyloxazolidine-2-thione, gave a high percentage of abnormal seedlings. The allelopathic potential of several species and cultivars of Brassica on wheat, in laboratory and field trials, has been reported by Mason-Sedun et al. (1986) and MasonSedun and Jeppson (1988). More recent papers have shown the allelopathic effect of Rapeseed (Brassica napus L.) water extracts on Phalaris minor (Retz.), Convolvulus arvensis (L.) and Sorghum halepense (L.) (Aliki et al., 2014).

Furthermore, Brassica DSMs have shown a good synergy with crude glycerin (CG), a underestimated co-product derived from the biodiesel chain. D'Avino et al. (2015a) reported the first attempts to apply CG as an active ingredient for germination inhibition (GI), even if high doses were required for a significant inhibition activity. On the other hand, the DSMs, activated by a patent procedure (Lazzeri et al. 2010), were easily formulated with CG solutions, maintaining a high GSLs conversion rate and a sufficient retention capacity of the biologically active compounds. 
In this way, the synergic effect of CG and DSMs allowed a strong reduction of CG in the formulations.

Black-grass (Alopecurus myosuriodes Huds.), a major annual grass weed of winter cereals, was chosen as a potentially interesting target. Its winter annual growth habit is well adapted to winter cereal production, and recent crop management techniques such as earlier fall planting and intensive cereal rotation have led to rapid increases in black-grass populations, (Holm et al., 1997). One of the first cases of resistance to herbicides registered in Europe was in early 1980s, in Essex, UK (Moss and Cussans, 1985). Nowadays, herbicide resistance in black-grass populations is reported in a number of EU countries, including populations that demonstrate multiple resistance to a range of herbicides with different modes of action, including photosystem II inhibitors, ACCase inhibitors, and ALS inhibitors (Henriet and Marechal, 2009; Keshtkara et al., 2015).

The aim of this work was to evaluate the GI activity on black-grass of different Brassica DSMs in formulation with and without CG. Before the evaluation of the effect of five Brassica DSMs on black-grass, a preliminary screening by in vitro and glasshouse trials on lettuce was set up to evaluate the antigerminative capability of twenty GSL containing DSMs from the CREA-CI collection. The proposed treatments could represent an interesting and novel natural alternative to conventional approaches in weed control.

\section{Materials and methods}

\subsection{Materials}

The CG was purchased from Cerealdocks S.p.A. (Vicenza, Italy), an industrial biodiesel company and its composition was previously published (D'avino et al. 2015b). Berteroa incana (L.) DC., Brassica oleracea L., Brassica rapa L., Brassica tournefortii Gouan, Eruca sativa Mill., Erysimum pseudorhaeticum Polatschek, Hesperis matronalis L., Lepidium campestre (L.) W.T. Aiton, Lepidium densiflorum Schrad., Lepidium sativum L., Lesquerella fendleri L., Limnanthes alba Benth., Raphanus sativus L., Rapistrum rugosum (L.) All., Camelina sativa (L.) Crantz, Cleome 
hassleriana Chodat, Reseda lutea L., and Sisymbrium officinale (L.) Scop. DSMs derived from the CREA-CI Brassicas collection (Lazzeri et al., 2013) were defatted with hexane (1/3, W/V) overnight at room temperature $\left(21 \pm 1{ }^{\circ} \mathrm{C}\right)$. Before defatting, Rapistrum rugosum seeds were scarified with a grinder (Bühler-Miag, MLI-204) to remove the very corky no-GSLs containing silique. Sinapis alba L. DSM from the CREA-CI Brassicas collection, and Brassica nigra (L.) W.D.J. Koch DSM purchased by Agrium Italia S.p.A (Livorno), were produced after seed defatting by an endless screw press in which temperature was kept lower than $75^{\circ} \mathrm{C}$ (Lazzeri et al., 2010). Lettuce (Lactuca sativa L. cv. Cosmic) was purchased from SAIS S.p.A. (Cesena, Italy), whilst Alopecurus myosuriodes Huds. black-grass, (population: Blackgrass Foxtail, Slender) was purchased from Herbiseed (Reading, UK).

\subsection{Defatted seed meals characterization}

All DSMs were produced by a patented procedure (Lazzeri et al., 2010) aimed at optimizing the enzymatic system that catalyzes GSL hydrolysis. The preparation details must be considered as commercially confidential and their property is of Agrium Italia S.p.A (Livorno). The DSMs were analyzed according to the following methods:

- Dry matter was determined by oven-drying the DSM at $105^{\circ} \mathrm{C}$ for $12 \mathrm{~h}$ and evaluating the difference in weight before and after treatment;

- Residual oil content was determined by the standard Soxhlet extraction method using hexane as solvent;

- Nitrogen content was determined by the Kjeldahl method (Standard UNI 22604, 1992), using a Tecator digestion system 20 and an automatic Büchi distillation unit (B-324);

- Glucosinolate content was determined following the ISO 9167-1 method (ISO 9167), with some minor modifications in the extraction phase, as described in Lazzeri et al. (2011).

All data are reported as mean \pm standard deviation of four determinations. 


\subsection{In vitro trials: extract preparation and hydrolysis product GC-MS identification}

\subsubsection{Extract preparation}

Water suspensions of each DSM $\left(15 \mathrm{~g} \mathrm{~L}^{-1}\right)$ were kept under agitation on an orbital shaker, $0.22 \mathrm{~g}$ for 40 minutes, at room temperature $\left(21 \pm 1^{\circ} \mathrm{C}\right)$. The suspensions were centrifuged at $3893 \mathrm{~g}$, for 30 minutes and filtered with filter paper (Filter-Lab, 1248).

\subsubsection{Deactivation of defatted seed meals}

A small batch of DSM was treated in sealed borosilicate glass containers by an autoclave (20 minutes, $120^{\circ} \mathrm{C}$ ) in order to deactivate the myrosinase enzyme and prevent GSLs hydrolysis to bioactive compounds. Extracts from deactivated DSMs were prepared as reported above.

\subsubsection{Hydrolysis product GC-MS identification}

Samples of the obtained aqueous extracts $(500 \mu \mathrm{L})$ were mixed with ethyl acetate (LC-MS Chromasolv ${ }^{\circledR}$ ) at a ratio of 1:1 and after agitation with a vortex for 3 min were centrifuged for 10 min at $1240 \mathrm{~g}$. One $\mu \mathrm{L}$ of the upper organic phase was than collected and injected in a Bruker GC451 Gas Chromatograph equipped with a HP-5 fused silica capillary column $(30 \mathrm{~m}, 0.25 \mathrm{~mm}$ inside diameter, $0.25 \mu \mathrm{m}$ film thickness, Scientific Inc, Folsom, CA) connected to a quadrupole mass detector Bruker SCION SQ Premium (Bruker Daltonics, Macerata, Italy). The oven temperature was set at $40^{\circ} \mathrm{C}$ and maintained for $4 \mathrm{~min}$, then it was programmed to rise from 40 to $220{ }^{\circ} \mathrm{C}$ at $10^{\circ} \mathrm{C} \min ^{-1}$ and finally held at $220^{\circ} \mathrm{C}$ for $4 \mathrm{~min}$. Transfer line $280^{\circ} \mathrm{C}$, ion source $220^{\circ} \mathrm{C}$, split injection (1:20), carrier gas (Helium) $1 \mathrm{ml} \mathrm{min}^{-1}$ were applied. The mass spectrometer was operated in electron impact mode at $70 \mathrm{eV}$, scanning range $10-250 \mathrm{Mz}$, full scan acquisition mode. Compounds were identified by matching the recorded mass spectra with the NIST/EPA/NIH Mass Spectral Database (NIST11, GAITHERSBURG, MD) and by comparing retention time and spectra with reference standard compounds (Santa Cruz Biotechnology) analyzed in the same conditions.

\subsection{Preliminary in vitro trials: lettuce germination inhibition}


Preliminary in vitro trials on lettuce were set up to evaluate the antigerminative capability of twenty GSL containing DSMs from the CREA-CI collection. The experimental conditions in the trials were those reported in D'Avino et al. (2015a). The in vitro trials were carried out following the UNICHIM protocol (UNICHIM, 2003) with minor modifications. Ten lettuce seeds were placed in each Petri dish containing a filter paper (Filter-Lab, 1300/80, diam. 90mm) with $1.8 \mathrm{ml}$ of DSM extract. The Petri dishes were kept in the dark at $20 \pm 1^{\circ} \mathrm{C}$. After 7 days, the number of germinated seeds was counted. Each treatment was replicated five times. The extracts from deactivated DMSs were applied as control in the same experimental conditions in order to verify that the observed germination inhibition was mainly due to the GSL hydrolysis products activity. At the end of the trial, besides the number of germinated seeds, the epicotyl and primary root lengths of lettuce seedlings, treated with deactivated DSMs, were measured.

\subsection{Preliminary glasshouse trial: lettuce germination and growth inhibition}

The preliminary glasshouse experiment was performed in Bologna, Italy $\left(44^{\circ} 31^{\prime} \mathrm{N} 11^{\circ} 21^{\prime} \mathrm{E}\right)$ at CREA-CI. In this experiment, five DSMs (Brassica tournefortii, Brassica nigra, Eruca sativa, Rapistrum rugosum, and Sinapis alba) were chosen among the most effective in previous trials, also depending on quantity of stocked seed for DSM production. The DSMs were applied, formulated with and without $\mathrm{CG}$, in plastic pots (high $9 \mathrm{~cm}$, diameter $9.5 \mathrm{~cm}, 250 \mathrm{ml}$ ). The pots were filled with $200 \mathrm{~g}$ of a mixture of $50 \%$ of sandy-loamy soil (clay13\%, silt 18\%, sand $69 \%$ ), $50 \%$ of peat (Floradur®, raised-bog-peat with $\mathrm{CaCl}_{2}, \mathrm{pH}$ ranging from 5 to 6.5) and $710 \mathrm{mg}$ of each DSM were mixed to the soil $\left(2.7 \pm 1 \mathrm{~g}\right.$ of DSM L ${ }^{-1}$ of soil). The DSM dose and the target seed were defined according to previous experiments, reported in D'Avino et al. (2015a) in which a similar glasshouse trial was performed. In each pot, 20 lettuce seeds were sown $1 \mathrm{~cm}$ deep in the dry soil. The experiment was carried out in a glasshouse under controlled conditions at $22 \pm 2^{\circ} \mathrm{C}$. The pots were watered with $24 \mathrm{ml}$ of tap water, a dose lower than soil field capacity, or treated only once with the same amount of a CG solution at $10 \%(9.2 \mathrm{ml} / \mathrm{L}$ of soil).The number of germinated seeds was 
measured 27 days after sowing. The root and above-ground biomass yield (on dry matter) were measured to assess the effect on the following plant growth. Each treatment was replicated three times.

\subsection{Black-grass in vitro trial}

A Petri dish trial was set up preparing an extract as above reported. Since the black-grass seeds need more time to germinate and, as other weeds, have a long dormancy, a different approach to the in vitro experiment was necessary. For these reasons, some modification to the protocol were defined: 150 black-grass seeds were soaked in the extracts for $24 \mathrm{~h}$ and kept in a growth chamber (Cooled Incubator MIR-154-PE, Panasonic Healthcare Co., Ltd, Jp), in the dark, at $20 \pm 1^{\circ} \mathrm{C}$. The day after, 20 seeds were surface sterilized with sodium hypochlorite 5\%, rinsed 2 times with sterile distilled water, and then placed in a Petri dish containing $3 \mathrm{ml}$ of distilled water. Each treatment was replicated five times. The Petri dishes were sealed with parafilm (Parafilm® ${ }^{\circledR}$ ) and kept in the dark, in the same growth chamber, at $20^{\circ} \mathrm{C}$. The number of germinated seeds was counted after 14 days.

\subsection{Black-grass glasshouse trial}

Further glasshouse experiments were performed at Harper Adams University, Newport, Shropshire, UK $\left(52^{\circ} 46^{\prime} \mathrm{N} 2^{\circ} 25^{\prime} \mathrm{W}\right)$. The effect on black-grass germination of five different DSMs $(B$. tournefortii, B. nigra, E. sativa, R. rugosum, and S. alba) formulated with and without CG was evaluated. The DSMs were applied in a pot experiment, mixed into the soil before sowing. Each pot (c.ca $300 \mathrm{ml}$ volume) used in this trial was filled with $200 \mathrm{~g}$ of a mix of $50 \%$ Horticultural Silver Sand (silica sand, CEM-SPEC LTD, Harby, Leics., UK) + 50\% John Innes No.2 soil-based compost for potting plants (J. Arthur Bower's products, William Sinclair Horticulture Ltd, Lincoln, UK). Three doses for each DSM were applied: i) $1.4 \pm 1$; ii) $2.7 \pm 1$; and iii) $5.5 \pm 1 \mathrm{~g} \mathrm{~L}^{-1}$ of soil. Fifty black-grass seeds were sown in each treated pot. The same three doses of DSM were applied in 
formulation with CG. In these pots $28 \mathrm{ml}$ of a $10 \% \mathrm{CG}$ solution was poured into the soil after sowing. The pots were kept in a glasshouse under controlled conditions, with light 16 hour a day (High Pressure Sodium lamp SON-T 400, with ignitor, $48000 \mathrm{Lm}$ ) and a temperature of $22 \pm 2{ }^{\circ} \mathrm{C}$. The amount of CG used was based on a previous experience (D'Avino et al., 2015a). Each treatment was replicated three times. After 8 days the number of germinated seeds was counted and plant heights and the dry matter produced by each pot were measured.

\subsection{Statistics}

All the experiments were organized in a randomized experimental design. In in vitro and in vivo trials, the effects on both lettuce and black-grass germination were expressed as germination inhibition (GI) percentages, a calculation of the germination reduction referred to the untreated control according to the Schneider-Orelli's formula (Püntener, 1981), as reported in the fallowing equation:

$G I(\%)=\left(\frac{\text { Mortality } \% \text { in treated Petri dish-Mortality } \% \text { in Control }}{100-\text { Mortality } \% \text { in Control }}\right) * 100$

Germination inhibition percentages, stem and root lengths and biomass weight measured in the trials were subjected to ANOVA and Tukey's post hoc test performed with R software (R version 3.00.00, The R Foundation for Statistical Computing) and $\mathrm{P}<0.05$ was considered statistically significant. The values are expressed as mean per Petri dish/pot \pm standard error (SE).

Data collected from the black-grass glasshouse trials were calculated as percentages of reduction:

i) GI: Schneider-Orelli's formula, equation (1);

ii) Height reduction (HRED)

$\operatorname{HRED}(\%)=\left(\frac{\text { mean plant height in treated pot-mean plant height in untreated control }}{\text { mean plant height in untreated control }}\right) * 100$

iii) Dry matter reduction (DMRED)

$\operatorname{DMRED}(\%)=\left(\frac{\text { mean DM per plant in treated pot-mean DM per plant in untreated control }}{\text { mean DM plant in untreated control }}\right) * 100$ 
231 The measured parameters GI, HRED, and DMRED were subjected to Factorial ANOVA performed 232 with $\mathrm{R}$ software (R version 3.00.00, The R Foundation for Statistical Computing), considered as a 233 result of the following separate factors: i) type of DSM, ii) DSM concentration and iii) CG. As a 234 significant level, a $\mathrm{P}$ value $<0.001$ was adopted.

\section{Results and Discussion}

3.1. Degradation products from defatted seed meals and their efficacy in germination inhibition of

lettuce seeds

Among the twenty tested DSMs in the preliminary in vitro experiment, nine meals, reported in the

grey box (table 1), were considered effective according to their GI percentage. The evaluation of different DSM extracts evidenced very different behavior for the effectiveness in GI, that was linked to the total GSLs content, as much as to the type of GSLs profile.

Insert Table 1 here

The five DSMs chosen for further experiments are reported in bold in table 1. An appreciable nitrogen content was found in each DSM, ranging from $6.1 \pm 0.1 \%$ (B. tournefortii DSM) to $7.8 \pm 0.1 \%$ ( $R$. rugosum DSM), as reported in table 2. This feature could possibly represent an interesting integration of $\mathrm{N}$ from conventional fertilizer, in open field conditions. Furthermore, Snyder et al. (2010) clearly reported that a high GSLs containing biomass incorporated in soils, through its capability to inhibit microbial respiration due to the GSLs degradation products release reduces the soil $\mathrm{N}$ nitrification. This support the importance of these Brassica DSMs as interesting fertilizing input. The composition and the low residual oil amount, lower than $10 \%$, could not imply a phytotoxic effect itself (Gauvirt \& Cabanne, 1993). 
258 After some preliminary GC-MS analyses of the degradation products in the DSM extracts applied in 259 the in vitro trials, some interesting results emerged. As expected, in the experimental reaction 260 conditions, the main degradation product of the B. nigra DSM extract was 2-propenyl ITC. The main degradation products in B. tournefortii, R. rugosum and E. sativa DSM extracts were 3methylsulfinylpropyl (iberin), 3-methylsulphonylpropyl (cheirolin) and 4-methyltiobutyl (erucin) ITCs, respectively. All the ITCs showed to remain stable for more than $24 \mathrm{~h}$ in a sealed bottle after the extract production, the same time spent to soak the black-grass seeds in in vitro trial ( $\$ 2.6)$, except for those from $S$. alba. In fact, no ITCs were found in the $S$. alba extract, according to the wide documented instability of 4-hydroxybenzyl ITC in aqueous solutions which results in a quick hydrolysis to benzylic alcohols and thiocyanate ion (Agerbirk and Olsen., 2012). Besides this paper, other studies had already shown an interesting effectiveness in weed containment induced by $S$. alba (Rice et al., 2016; Boydston et al., 2011), and even in the preliminary tests of this study S. alba DSM showed an interesting containment effect as well. In fact, in the in vitro trials, the active $S$. alba DSM totally inhibited lettuce seed germination as other DSMs, but the same meal after MYR deactivation did not shown any GI (table 3), confirming the fundamental role of GSL- MYR system (Angelini et al,, 1998).

As reported in Borek et al. (2005), 4-hydroxybenzylisothiocyanate hydrolyzes to parahydroxybenzyl alcohol and $\mathrm{SCN}^{-}$in presence of alkaline $\mathrm{pH}$ values, and this compound is probably responsible for the observed phytoxicity. At the same time, there is a light effect on the subsequent development of the sprouts treated with deactivated DSMs, on which a reduction of root and epicotyl lengths was observed. This activity could be probably due to other compounds involved in the phytotoxic effect (fig. 1). 
Insert Figure 1 here

285

286 The in vivo trials confirmed an interesting efficacy of the DSMs formulated with CG in controlling lettuce seed germination (fig. 2): from $95 \%$ of $B$. nigra and E. sativa treatments, to $80 \%$ of $S$. alba, even the CG applied alone showed a GI of $78 \%$. In this trial, only the addition of $B$. nigra or $E$. sativa to the formulation implied a statistically consistent reduction in germination compared to the CG applied alone, whilst the other meals had a slighter effect. In addition, all treatments, CG alone included as control, showed a dramatic reduction in dry biomass yield, from 20 to 100 times lower if compared to the biomass yield in the control pots (fig.2).

\section{Insert Figure 2 here}

3.2 Effectiveness of defatted seed meal extracts in black-grass germination inhibition: in vitro trials

The in vitro trials confirmed the potential effectiveness of Brassicas derived water extracts in weed control (Aliki et al., 2014) on both monocotyledons and dicotyledons. Furthermore, strong differences among DSM extracts in their efficacy in inhibiting black-grass germination (fig.3) emerged. In fact, after 15 days $S$. alba, R. rugosum and E. sativa DSMs did not differ from the untreated control showing a GI of $0 \%, 12 \%$ and 20\%, respectively. Brassica nigra, instead, totally inhibited the seed germination of black-grass $(\mathrm{GI}=100 \%)$, confirming the high efficacy observed on lettuce in previous trials.

Insert Figure 3 here

An unexpected result was related to the B. tournefortii DSM extract which, in Petri conditions, 308 showed a GI of $-48 \%$. 
3.3 Effectiveness of defatted seed meals formulated with glycerin in black-grass germination and growth inhibition: in vivo trials

The application of the DSM formulated with and without CG in semi-controlled conditions in greenhouse added some new information for a practical application of Brassica DSMs in weed control. The CG used in the trials had a glycerol content of around $80 \%$ and a residual water content of $14 \%$.The remaining components were mainly inorganic (ash 4\%) and no hazardous compounds were found, except for very low traces (D'Avino et al., 2015b). In this experiment, B. nigra DSM (5.5 $\mathrm{g} \mathrm{L}^{-1}$ of soil) formulated with a solution of $\mathrm{CG}$ at $10 \%\left(9.2 \mathrm{ml} \mathrm{L}^{-1}\right.$ of soil) completely inhibited the germination and the subsequent seedlings development until 4 weeks after the treatment. Even the B. nigra DSM, applied without CG, at the highest dose showed a GI of $97.9 \%$ after 4 weeks. Furthermore, with regard to the GI, B. nigra DSM applied both with and without CG showed a very clear dose/response effect on GI percentage (Fig. 4), unlike the other DSMs.

Whilst the effectiveness of the B. nigra DSM was clearly observed in our experiments, the high phytotoxic action of 2-propenyl-ITC compared to other ITCs has been reported in other publications. Oleszek (1987) and Bialy (1990), for instance, demonstrated that germinating seeds exposed to either pure 2-propenyl-ITC or the pulverized leaves of B. juncea or B. nigra, could be inhibited or, at least the overall growth of the seedlings was stunted. Although efficacy largely depends on persistence, release rate and intrinsic biological activity greatly influenced global effectiveness. Brassica nigra DSM effectiveness can also be linked to the high volatility of its main GSL degradation product (Sekiyama et al., 1993; Borek et al., 1994). Furthermore, this characteristic have also positive effects on soil such as higher resilience of microbial communities compared to chemical fumigants (D’Avino et al., 2004). On the other hand, different formulations 
could increase the DSMs effectiveness in GI, improving the mechanisms involved in the active compounds release. Moreover, a more precise dose/GI response assessment must be investigated.

Although in the in vitro trial an increased number of germinated seeds was measured after two weeks in Petri dishes treated with B. tournefortii, this did not occurred in glasshouse conditions. In fact, none of the three doses of $B$. tournefortii DSM tested in pot conditions increased the number of black-grass germinated seeds, nor height or dry weight of plants, compared to the untreated test (data not shown). Other studies are ongoing for a better understanding of the processes involved in this phenomenon.

All the meals, except for B. nigra DSM, did not show a clear dose/effect response, probably due to a reduced effectiveness in these specific assay conditions, but at the same time some meaningful results clearly emerged from the factorial ANOVA applied to the GI, HRED and DMRED measurements.

Firstly, the black-grass seed germination was inhibited by a complex interaction of factors. In fact, a statistically significant effect due to the DSM and CG factors, if considered separately, was observed. Although the GI was significantly affected by the interactions between i) ' $D S M$ ' $\mathrm{x}$ ' $D S M$ concentration', and ii) 'DSM concentration' $\mathrm{x}$ ' $C G$ ', the ' $C G$ ' was the unique factor which had a significant effect on plant growth parameters HRED and DMRED (Tab. 4).

\section{Insert Table 4 here}

The greenhouse trial showed how the presence of DSM in the treatments affected mainly the early stages of black-grass seed development. In fact, the interactions between the factors of the factorial ANOVA i) type of 'DSM', ii) 'DSM concentration' and iii) presence or absence of 'CG', which affected seed germination, resulted very complex. Once the seedlings emerged, the subsequent growth (plant height and biomass) was mostly affected by the presence of CG in the formulations. These results confirmed the limited persistence of the effect of GSL degradation products in the soil 
and consequently the safety of the application of Brassicaceae DSMs in weed control. The concerning about CG utilization is based upon methanol and sodium residues, used as catalysts in the biodiesel production process, but few traces were found in the batch used for the trials. Thus, CG is considered a safe product that can be used, for instance, as an energy-rich feed component in animal diets (Alexander et al., 2010).

Since the B. nigra DSM, the most effective tested meal, showed a total GI at the same concentration and conditions as the other DSMs, higher concentrations were not investigated. As previously stated, the effectiveness of the DSMs depends also on the optimization of the formulation, and under different experimental conditions (e.g. higher concentration, different pH, type of distribution), it could greatly increase.

\section{Conclusions}

Novel alternatives to conventional herbicides are strongly needed. Nowadays, weed control without herbicides is carried out mostly through physical (cultural) methods associated to high energy and time consumption. Whilst studies have been carried out on pests and pathogens with bio-based treatments, fewer studies have been undertaken on weed control. The in vitro and in vivo results of this study confirmed the effectiveness of a $100 \%$ bio-based formulation in the containment of blackgrass, a weed with a high resistance to common herbicides.

The potential of Brassica derived DSMs in weed control has to be considered with great attention for different reasons: i) the proposed formulations are completely bio-based products that could be considered not only for conventional farming, but even admitted both in integrated pest management and organic farming (where no herbicides are allowed); ii) they present a combined effect both on weeds and on soilborne pests and diseases; iii) formulated Brassicaceae DSMs could also represent an interesting integration to fertilizers with their extremely balanced nitrogen content. All these aspects, applied within a virtuous biofumigant cropping system, make the use of DSMs in agriculture an interesting innovative proposal. 


\section{Acknowledgements}

This work was carried out within the activities of the Research project financed by Agrium Italia S.p.A (Livorno) coordinated by CREA-CI of Bologna, Italy.

\section{References}

Agerbirk, N., Olsen, C.E., 2012. Glucosinolates structure in evolution.Phytochemistry 77, 16-45. doi: 10.1016/j.phytochem.2012.02.005

Alexander, J., Benford, D., Boobis, A., Ceccatelli, S., Cravedi, J.-P., Doerge, D., Dogliotti, A. di D.E., Edler, L., Farmer, P., Filipic, M., Fink-Gremmels, J., Fürst, P., Guerin, T., Knutsen, H.K., Machala, M., Mutti, A., Schlatter, J., Leeuwen, R. Van, 2010. Scientific Opinion on the abiotic risks for public and animal health of glycerine as co-product from the biodiesel production from Category 1 animal by-products ( $\mathrm{ABP}$ ) and vegetable oils. Eur. food Saf. Auth. J. 8, 1-22. doi:10.2903/j.efsa.2010.1934.

Aliki, H.M., Reade, J.P.H.; Back, M.A., 2014. Effects of concentrations of Brassica napus (L.) water extracts on the germination and growth of weed species. Allelopathy Journal. 34, Issue 2, 287-298.

Angelini, L.; Lazzeri, L.; Galletti, S.; Cozzani, A.; Macchia, M.; Palmieri, S., 1998: Antigerminative activity of three glucosinolate-derived products generated by myrosinase hydrolysis. Seed Science \& Technology 26(3): 771-780.

Bialy, Z., Oleszek, W., Lewis, J., Fenwick, G. R., 1990. Allelopathic potential of glucosinolates (mustard oil glycosides) and their degradation products against wheat. Plant and Soil, 129, Issue 2, pp 277-281.

Bones, A.M., Rossiter, J.T., 2006. The enzymic and chemically induceddecomposition of glucosinolates. Phytochemestry 67, 1053-1067.

Borek, V., Morra, M.J., Brown, P.D., McCaffrey, J.P., 1994. Allelochemicals produced during sinigrin decomposition in soil. J. Agric. Food Chem., 42, pp. 1030-1034.

Borek, V., Morra, M.J., 2005. Ionic thiocyanate ( $\left.\mathrm{SCN}^{-}\right)$production from 4-hydroxybenzyl glucosinolate contained in Sinapis alba seed meal. J. Agr. Food Chem. 47:3837-3842.

Boydston, R.A., Morra, M.J., Borek, V., Clayton, L. and Vaughn, S.F., 2011. Onion and Weed Response to Mustard (Sinapis alba) Seed Meal, Weed Science, 59(4), pp. 546-552. doi: 10.1614/WS-D-10-00185.1.

Campbell, A.G., 1959. A Germination Inhibitor and Root-Growth Retarder in Chou Moellier (Brassica oleracea var.). Nature 183, 1263-1264. doi:10.1038/1831263a0.

D’Avino L., Gaggi C., Leoni O., Cinti S., Lazzeri L., 2004. Effects of biofumigation with allyl 
isothiocyanate producing plants on soil biological quality: environmental fate, ecotoxicology and evaluation via QBS Index. Agroindustria, vol. 3, n 3. 5-8.

D’Avino, L., Matteo, R., Malaguti, L., Pagnotta, E., Righetti, L., Ugolini, L., Lazzeri, L., $2015 a$. Synergistic inhibition of the seed germination by crude glycerin and defatted oilseed meals. Ind. Crops Prod. 75, 8-14.

D' Avino, L., Rizzuto, G., Guerrini, S., Sciaccaluga, M., Pagnotta, E., Lazzeri, L., $2015 b$. Environmental implications of crude glycerin used in special productsfor the metalworking industry and in biodegradable mulching films. Ind. Crops Prod. 75, 29-35.

Directive 2009/128/EC of the European Parliament and of the Council of 21 October 2009 establishing a framework for Community action to achieve the sustainable use of pesticides (Text with EEA relevance). Official Journal of the European Union, L 309, 24 November 2009.

European Commission, Regulation No 1907/2006 of the European Parliament and of the Council of 18 December 2006 concerning the Registration, Evaluation, Authorisation and Restriction of Chemicals (REACH). http://eur-lex.europa.eu/legalcontent/EN/TXT/PDF/?uri=CELEX:02006R1907-20140410\&from=EN. (Accessed 13 Feburary 2017).

Furlan, L., Bonetto, C., Finotto, A., Lazzeri, L., Malaguti, L., Patalano, G., Parker, W., 2010. The efficacy of biofumigant meals and plants to control wirewormpopulations. Ind. Crop Prod. 31, 245-254.

Gauvrit, C., Cabanne, F., 1993. Oils for weed control: Uses and mode of action. Pestic. Sci., vol. 37, Issue 2, 147-153

Henriet F., Marechal P.Y., 2009. Black-grass resistance to herbicides: three years of monitoring in Belgium. Commun. Agric. Appl. Biol. Sci.;74(2), 471-8.

Holm L, Doll J, Holm E, Pancho J, Herberger J, 1997. World Weeds. Natural Histories and Distribution. New York, USA: John Wiley and Sons, Inc.

International Organization for Standardization, ISO, 1992. Rapeseeds - Determination of Glucosinolates Content - Part 1: Method using High-Performance Liquid Chromatography. ISO 9167-1, 1-9.

Keshtkar E:, Mathiassen S.K., Moss S.R., Kudsk P., 2015. Resistance profile of herbicide-resistant Alopecurus myosuroides (black-grass) populations in Denmark. Crop Protection, 69, 83-89.

Kirkegaard, J.A., Gardner, P.A., Desmarchelier, J.M., Angus, J.F., 1993. Biofumigation using Brassica species to control pests and diseases in horticulture and agricul- ture. In: Wratten, N., Mailer, R.J. (Eds.), Proceedings 9th Australian Research Assembly on Brassicas. Agricultural Research Institute, Wagga Wagga, pp. 77-82

Lazzeri, L., Baruzzi, G., Malaguti, L., Antoniacci, L., 2003. Replacing methyl-bromidein annual strawberry production with glucosinolate containing green manure crops. Pest Manag. Sci. 59 (9), 983-990.

Lazzeri, L., Curto, G., Dallavalle, E., D’Avino, L., Malaguti, L., Santi, L., Patalano, G.,2009. Nematicidal efficacy of biofumigation by defatted Brassicaceae meal forcontrol of Meloidogyne incognita (Kofoid et White) Chitwon zucchini crop. J.Sustain. Agric. 33, 349- 
Lazzeri, L., Leoni, O., Manici,L.M., Palmieri, S., Patalano, G. 2010. Use of Seed Flour as Soil Pesticide Patent n॰US 7749549.

Lazzeri, L., D’Avino, L., Ugolini, L., De Nicola, G.R., Cinti, S., Malaguti, L., Bagatta, M.,Patalano, G., Leoni, O., 2011. Bio-based products from Brassica carinata A Braun Oils and Defatted Meals by a Second Generation Biorefinery Approach. EU BCand E Conference Proceedings, 1080-1092.

Lazzeri L., Bagatta, M., D’Avino, L., Ugolini, L., De Nicola, G.R., Casadei, N., Cinti, S., Malaguti, L., Matteo, R., and Iori, R., 2013. Characterization of the Main Glucosinolate Content and Fatty Acid Composition in Non Food Brassicaceae Seeds, Acta Horticulturae: 1005: 331-338.

Maity, S.K., 2015. Opportunities , Recent Trends and Challenges of Integrated Biorefinery : Part I Opportunities, recent trends and challenges of integrated biorefinery: Part I 43, 1427-1445.

Mason-Sedun, W., Jessop, R., \& Lovett, J. 1986. Differential phytotoxicity among species and cultivars of the genus Brassica to wheat: I. Laboratory and field screening of species. Plant and Soil, 93(1), 3-16. Retrieved from http://www.jstor.org/stable/42936257

Mason-Sedun, W., \& Jessop, R. 1988. Differential phytotoxicity among species and cultivars of the genus Brassica to wheat: II. Activity and persistence of water-soluble phytotoxins from residues of the genus Brassica. Plant and Soil, 107(1), 69-80. Retrieved from http://www.jstor.org/stable/42937419

Moss S.R., Cussans G.W., 1985. Variability in the susceptibility of Alopecurus myosuroides (black-grass) to chlorotoluron and isoproturon. Asp. Appl. Biol., 9, 91.

Ngala, B.M., Woods, S.R., Back, M.A., 2015. Sinigrin degradation and G. pallida suppression in soil cultivated with brassicas under controlled environmental conditions. Appl. Soil Ecol. 95, 9-14. doi:http://dx.doi.org/10.1016/j.apsoil.2015.05.009.

Oleszek, W., 1987. Allelopathic effects of volatiles from some Cruciferae species on lettuce, barnyard grass and wheat growth. Plant and soil. 102, Issue 2, pp 271-273.

Püntener W., 1981 Manual for field trials in plant protection second edition. Agricultural Division, Ciba-Geigy Limited.

Rice, A.R., Thill, D.C., Morra, M.J., 2016. Vegetable crop emergence and weed control following amendment with different Brassicaceae seed meals 22, 5-7. doi:10.1017/S1742170507001743.

Sekiyama, Y., Mizukami, Y., Takada, A., Numata, S. 1993. Vapor pressure and stability of allyl isothiocyanate. J Food Hyg Soc Japan 35, pp. 365-370.

Service R.F., 2013. What Happens When Weed Killers Stop Killing?. Science 341, 6152, pp 1329. doi: 10.1126/science.341.6152.1329.

Snyder A.J., Johnson-Maynard J.L., Morra M.J., 2010. Nitrogen mineralization in soil incubated with 15N-labeled Brassicaceae seed meals. Applied Soil Ecology. 46(1), 73-80.

Standard UNI 22604. 1992. Seed and vegetable oils and derived products. Vegetable proteins. Determination of crude protein. 
UNICHIM, 2003. Method UNICHIM 1651 Water quality. In: Determination of Inhibition of the Germination and the Radical Elongation in Cucumis sativus L.(cucumber), Lepidium sativum L. (watercress), Sorghum saccharatum Moench (sorghum). Chronic Toxicity Test Short. UNICHIM, pp. 22.

\section{Highlights}

- Formulated Brassica defatted seed meals and glycerin reduce black-grass germination.

- Brassicaceae oilseed cakes could represent an alternative to conventional herbicides.

- Brassica nigra was the most effective defatted seed meal in germination inhibition.

- The glucosinolate-myrosinase system could be effectively applied in weed control.

\section{Figures}

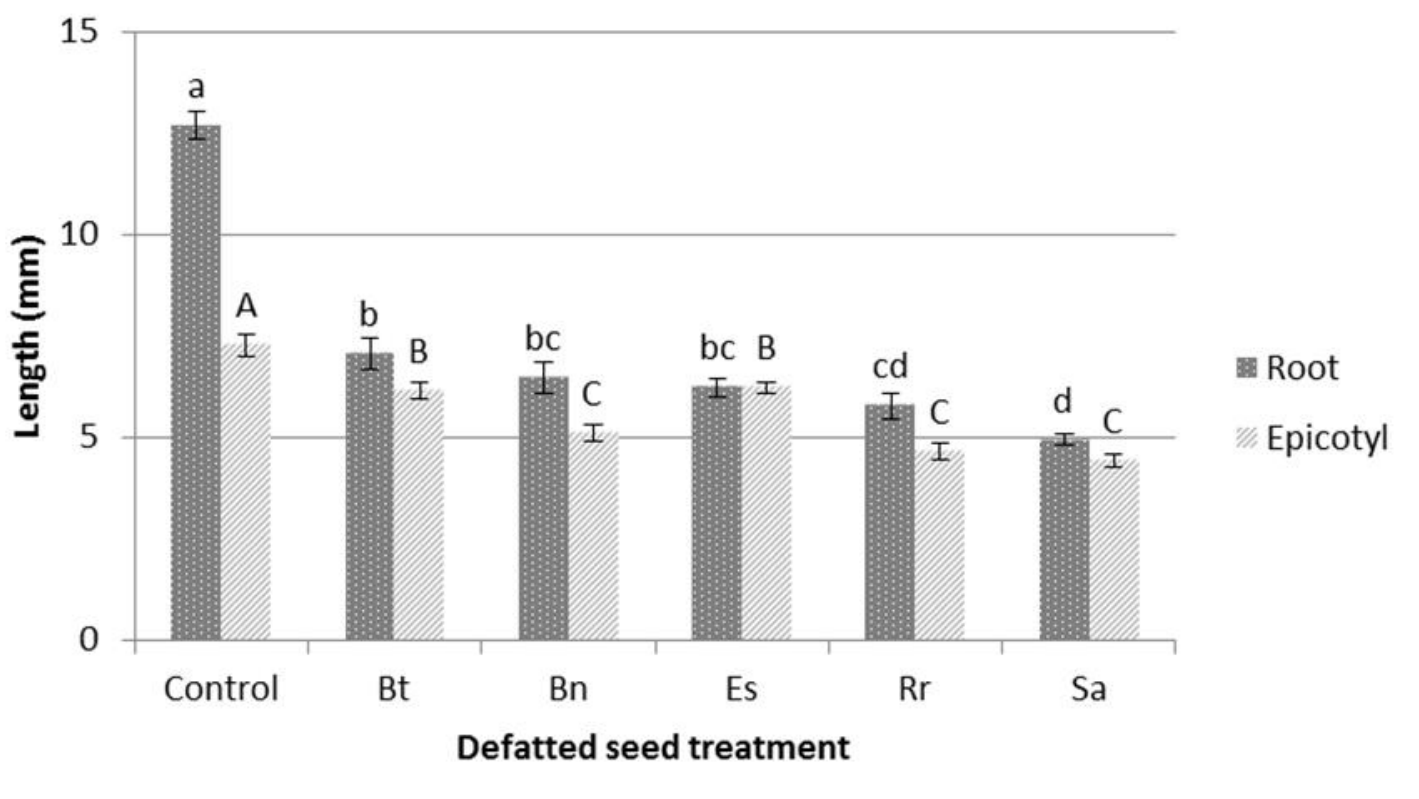

Fig. 1. In vitro experiment, lettuce root and epicotyl length after the application of the extracts from the deactivated DSMs: Brassica tournefortii (Bt); Brassica nigra (Bn); Eruca sativa (Es); Rapistrum rugosum (Rr); Sinapis alba (Sa). Different letters indicate a significant difference between treatments applying ANOVA and Tukey's test $(\mathrm{P}<0.05)$ on measured values. Uppercase letters refer to the epicotyl lengths, lower case letters refer to the root lengths. Error bar indicates standard error. 


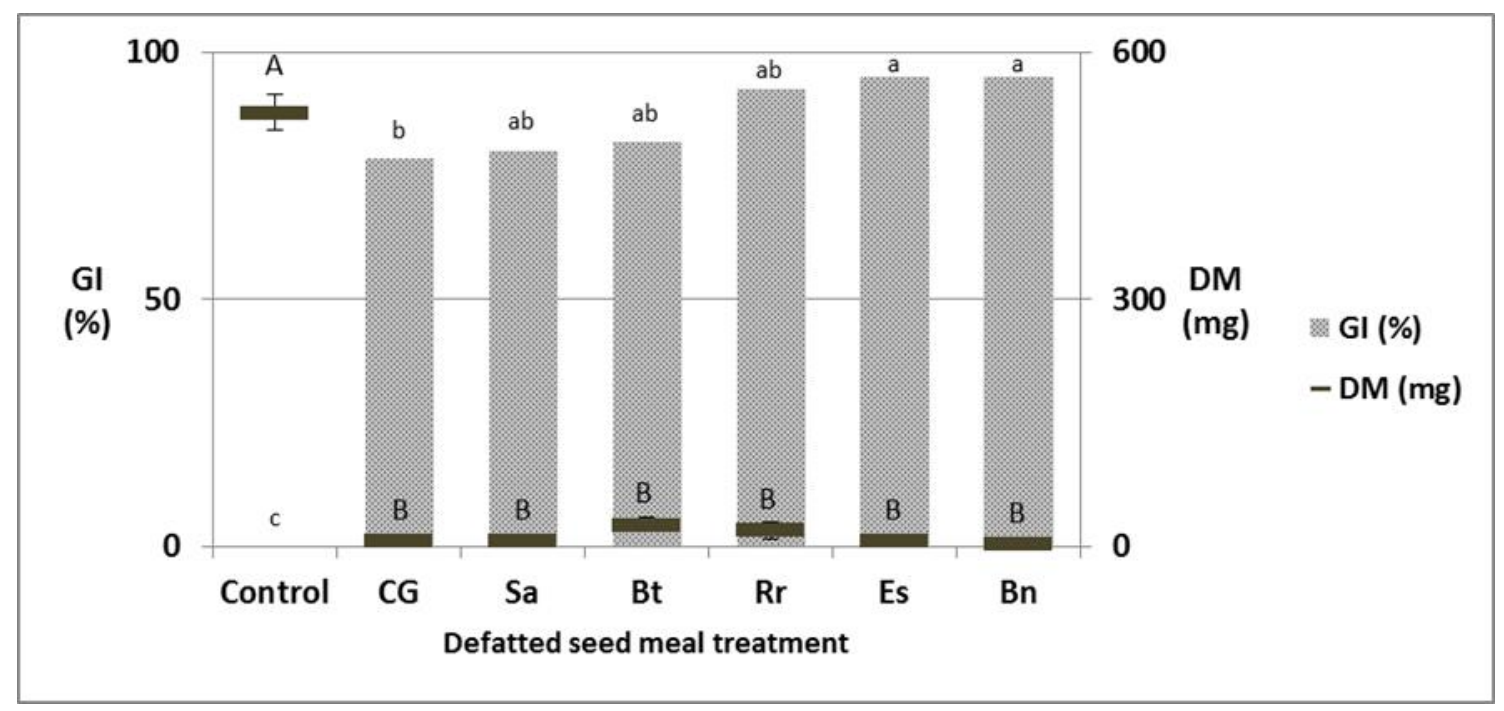

527 Fig. 2. Glasshouse experiment, showing application of different defatted seed meals $2.7 \mathrm{~g} / \mathrm{L}$ of soil, applied in formulation with a solution of crude glycerin (CG) at $10 \%(9.2 \mathrm{ml} / \mathrm{L}$ of soil) in lettuce pots. Germination inhibition (GI) and biomass dry matter yield (DM) are expressed as mean per pot. Different letters indicate a significant difference between treatments applying ANOVA and Tukey's test $(\mathrm{P}<0.05)$ on GI and DM. Uppercase letters refer to the dry matter production, lower case letters refer to the GI. Abbreviations: Brassica tournefortii (Bt); Brassica nigra (Bn); Eruca sativa (Es); Rapistrum rugosum (Rr); Sinapis alba (Sa). Error bar indicates standard error.

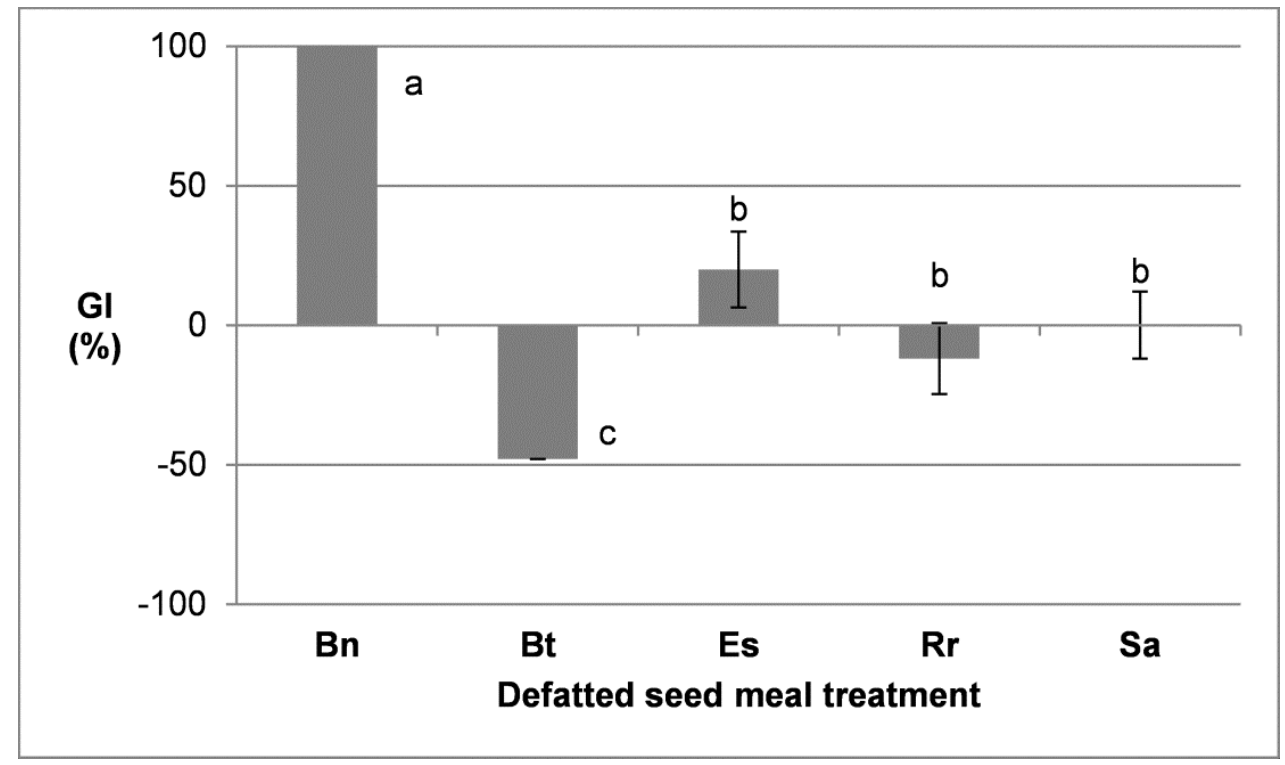

538 Fig. 3. In vitro experiment, black-grass Germination inhibition (\%) after the application of defatted seed meal extracts $(15 \mathrm{mg} / \mathrm{ml})$ expressed as mean per Petri dish. Different letters indicate a significant difference between treatments applying ANOVA and Tukey's test $(\mathrm{P}<0.05)$ on GI 
percentages. Abbreviations: Brassica tournefortii (Bt); Brassica nigra (Bn); Eruca sativa (Es);

542 Rapistrum rugosum (Rr); Sinapis alba (Sa). Error bar indicates standard error.

543

544

545

546

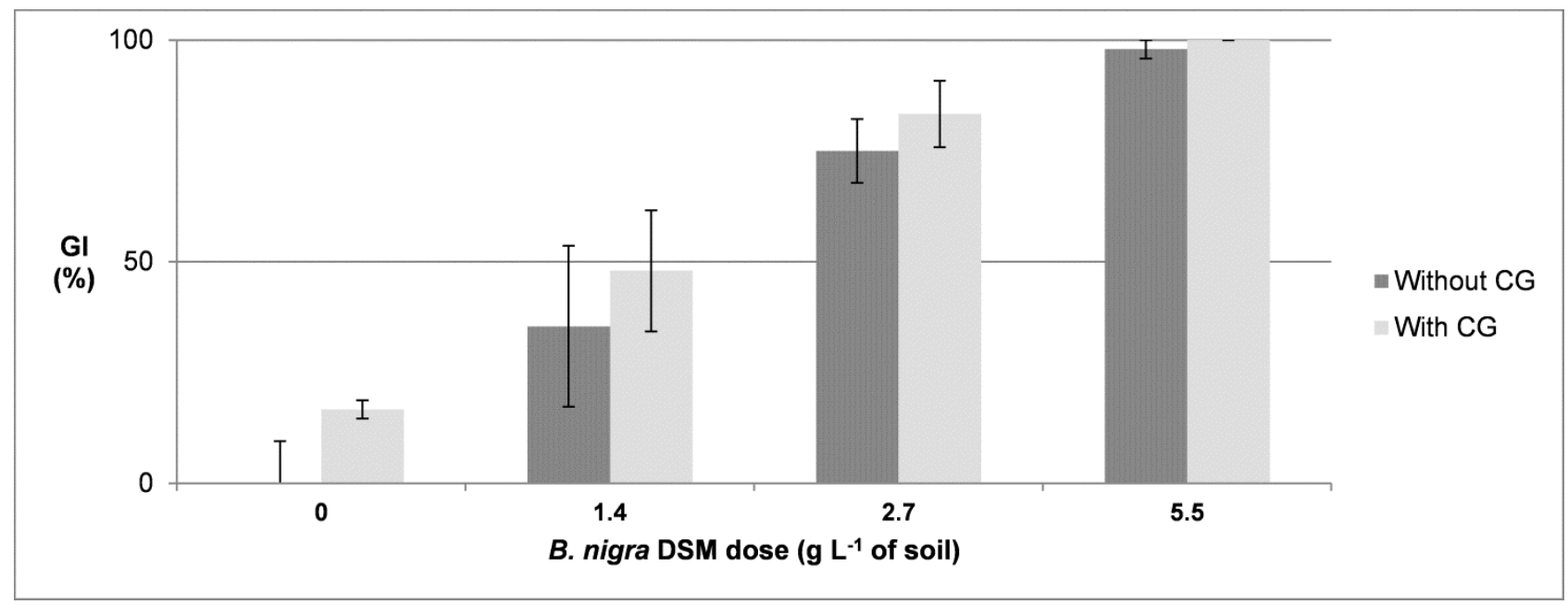

547 Fig. 4. Glasshouse experiment, showing the effect of applying Brassica nigra defatted seed meal 548 (DSM) formulated at three different doses (mg/pot), with and without crude glycerin (CG) on 549 black-grass (Alopecurus myosuroides Huds.) germination inhibition (GI\%). Black-grass 550 germination inhibition (GI) is expressed as mean per pot. Error bar indicates standard error. 


\section{Table 1}

555 Main glucosinolate (GSL) content of defatted seed meals (DSMs) and the germination inhibition 556 (GI) produced by the DSM extract on lettuce under in vitro conditions.
DSM
GSL
GSL
GSLs
GI

R-chain

Common name

$(\mu \mathrm{mol} / \mathrm{g})$

(\%)

\begin{tabular}{|c|c|c|c|c|}
\hline Brassica nigra & 2-propenyl & Sinigrin & $129.0 \pm 2.5$ & $100.0 \pm 0.0 \mathrm{~b}$ \\
\hline Brassica oleracea & 4-methylsulfinylbutyl & Glucoraphanin & $103.1 \pm 6.8$ & $100.0 \pm 0.0 \mathrm{~b}$ \\
\hline Brassica tournefortii & 3-methylsulfinylpropyl & Glucoiberin & $128.5 \pm 3.5$ & $100.0 \pm 0.0 \mathrm{~b}$ \\
\hline Eruca sativa & 4-methyltiobutyl & Glucoerucin & $152.0 \pm 2.5$ & $90.0 \pm 10.0 \mathrm{~b}$ \\
\hline Lepidium campestre & 4-hydroxybenzyl & Sinalbin & $139.6 \pm 0.6$ & $100.0 \pm 0.0 \mathrm{~b}$ \\
\hline Lepidium sativum & benzyl & Glucotropaeolin & $160.3 \pm 5.4$ & $100.0 \pm 0.0 \mathrm{~b}$ \\
\hline Raphanus sativus & 4-methylsulfinylbutyl-3-enyl & Glucoraphenin & $140.0 \pm 3.3$ & $100.0 \pm 0.0 \mathrm{~b}$ \\
\hline Rapistrum rugosum & 3-methylsulphonylpropyl & Glucocheirolin & $232.2 \pm 1.6$ & $100.0 \pm 0.0 \mathrm{~b}$ \\
\hline Sinapis alba & 4-hydroxybenzyl & Sinalbin & $187.2 \pm 1.1$ & $100.0 \pm 0.0 \mathrm{~b}$ \\
\hline Berteroa incana & 5-methylthiopentyl & Glucoberteroin & $86.6 * \pm 0.4$ & $24.0 \pm 0.0 \mathrm{a}$ \\
\hline Brassica rapa & but-3-enyl & Gluconapin & $156.1 \pm 3.4$ & $14.0 \pm 14.0 \mathrm{a}$ \\
\hline Hesperis matronalis & unknown & - & $236.9 * \pm 6.1$ & $22.0 \pm 5.8 \mathrm{a}$ \\
\hline Lepidium densiflorum & unknown & - & $188.4 * \pm 0.9$ & $12.0 \pm 5.8 \mathrm{a}$ \\
\hline Lesquerella fendleri & 3-methylsulfinylpropyl & Glucoiberin & $27.2 * \pm 0.6$ & $4.0 \pm 2.4 \mathrm{a}$ \\
\hline Limnanthes alba & 3-methoxybenzyl & Glucolimnanthin & $200.4^{*} \pm 2.9$ & $14.0 \pm 4.0 \mathrm{a}$ \\
\hline Camelina sativa & 10-methylsulfinyldecyl & Camelinin & $45.8 * \pm 1.9$ & $0.0 \pm 0.0 \mathrm{a}$ \\
\hline Cleome hassleriana & methyl & Glucocapparin & $77.65 \pm 0.2$ & $0.0 \pm 0.0 \mathrm{a}$ \\
\hline Erysimum pseudorhaeticum & Unknown & - & $110.0 \pm 5.4$ & $0.0 \pm 0.0 \mathrm{a}$ \\
\hline Reseda lutea & Unknown & - & $30.2 * \pm 0.1$ & $0.0 \pm 0.0 \mathrm{a}$ \\
\hline Sisymbrium officinale & isopropyl & Glucoputranjivin & $59.3 \pm 0.4$ & $0.0 \pm 0.0 \mathrm{a}$ \\
\hline
\end{tabular}

$557 *$ no relative proportionality factor known for sinigrin, the coefficient was arbitrary considered equal 558 to 1 . 
Table 2

560 Defatted seed meal characterization (mean \pm standard deviation)

\begin{tabular}{ccccccc}
\hline DSM & & B. nigra & B. tournefortii & E. sativa & R. rugosum & S. alba \\
\hline Oil content & \% DM & $8.9 \pm 0.1$ & $5.0 \pm 0.1$ & $9.4 \pm 0.3$ & $10.4 \pm 0.0$ & $5.7 \pm 0.0$ \\
Nitrogen content & $\%$ DM & $7.0 \pm 0.1$ & $6.1 \pm 0.1$ & $6.4 \pm 0.1$ & $7.8 \pm 0.1$ & $6.8 \pm 0.1$ \\
\hline
\end{tabular}

Abbreviations: Defatted seed meal (DSM); dry matter (DM);

\section{Table 3}

566 Effect on Lettuce in vitro germination (GI\%) (mean \pm standard error) of extracts from DSMs. The 567 main GSL degradation products from each DSM were analyzed by GC-MS and retention times are reported in the table.

\section{DSM GI\% Main GSL degradation product Retention time}

\begin{tabular}{lccc}
\hline A Brassica nigra & $100.0 \pm 0.0$ & 2-propenyl-isothiocyanate-ITC & 5.33 \\
A Brassica tournefortii & $100.0 \pm 0.0$ & 3-methylsulfinylpropyl-ITC & 18.74 \\
A Eruca sativa & $90.0 \pm 1.0$ & 4-methyltiobutyl-ITC & 15.03 \\
A Rapistrum rugosum & $100.0 \pm 0.0$ & 3-methylsulphonylpropyl-ITC & 18.28 \\
A Sinapis alba & $100.0 \pm 0.0$ & - & - \\
D Brassica nigra & $6.7 \pm 6.7$ & - & - \\
D Brassica tournefortii & $0.0 \pm 0.0$ & - & - \\
D Eruca sativa & $0.0 \pm 0.0$ & - & - \\
D Rapistrum rugosum & $0.0 \pm 0.0$ & - & - \\
D Sinapis alba & $0.0 \pm 0.0$ & - & - \\
\hline
\end{tabular}

Abbreviations: Defatted seed meal (DSM); Activated Myrosinase (A); Deactivated Myrosinase (D); 
573 Interaction between factors and their relevance in black-grass germination and development in the 574 glasshouse trial.

\begin{tabular}{lccc}
\hline \multicolumn{1}{c}{ Factorial ANOVA P value } & GI & HRED & DMRED \\
\hline DSM & & & \\
DSM concentration & $<\mathbf{0 . 0 0 1}$ & $>0.05$ & $<0.01$ \\
Crude Glycerin & $>0.05$ & $<0.05$ & $<0.05$ \\
DSM $x$ DSM concentration & $<\mathbf{0 . 0 0 1}$ & $<\mathbf{0 . 0 0 1}$ & $<\mathbf{0 . 0 0 1}$ \\
DSM $x$ Crude Glycerin & $<\mathbf{0 . 0 0 1}$ & $>0.05$ & $>0.05$ \\
DSM concentration $x$ Crude Glycerin & $<\mathbf{0 . 0 0 1}$ & $<0.05$ & $>0.05$ \\
DSM $x$ DSM concentration $x$ Crude Glycerin & $>0.05$ & $>0.05$ & $>0.05$ \\
\hline
\end{tabular}

575 576 577 578 